\title{
Preparation of Polymer-Bound Dinitrogen Complexes by Direct Reactions of Polymer-Metal Complexes with Molecular Nitrogen
}

\author{
Yoshimi Kurimura, Yasuhide UCHINO, Fumihiko OHTA, \\ Chikako SAITO, Mikio KoIDE,* \\ and Eishun TSUCHIDA* \\ Department of Chemistry, Ibaraki University, \\ 2-1-1, Bunkyo, Mito, Ibaraki 310, Japan. \\ * Department of Polymer Chemistry, Waseda University, \\ 3-4-1, Ohkubo, Shinjuku-ku, Tokyo 160, Japan.
}

(Received June 30, 1980)

\begin{abstract}
Polymer-bound dinitrogen complexes were synthesized directly from the polymer-bound ( $\eta^{5}$-vinylmethylcyclopentadienyl)tricarbonylmanganese analogues and molecular nitrogen in tetrahydrofuran (THF)/benzene $(1: 5 \mathrm{v} / \mathrm{v})$ under $3 \mathrm{~atm}$ of $\mathrm{N}_{2}$ at $2^{\circ} \mathrm{C}$. Dinitrogen complexes were also prepared by the oxidation of the hydrazine coordinated to the polymer-bound manganese complexes with hydrogen peroxide in the presence of cupric ions. The polymer-bound dinitrogen complexes are considerably stable compared to that of the corresponding monomer model of $\left(\eta^{5}\right.$-methylcyclopentadienyl)dicarbonyldinitrogenmanganese.
\end{abstract}

KEY WORDS Dinitrogen / Polymer Complex / Nitrogen Molecule / Manganese / Nitrogen Fixation /

A large number of dinitrogen complexes of transition metals have been synthesized and reduction of the coordinated nitrogen molecules to ammonia, hydrazine, and some organic nitrogen compounds have been investigated by many workers. Among these dinitrogen complexes, $\left(\eta^{5}-\right.$ cyclopentadienyl)dicarbonyldinitrogenmanganese $\left(\mathrm{CpMn}(\mathrm{CO})_{2} \mathrm{~N}_{2}\right)^{1-3}$ is a remarkable compound having the potentiality for becoming a catalyst in nitrogen fixation. ${ }^{4,5}$ Sellmann and Weiss ${ }^{2}$ suggested that, in principle, an organic nitrogen compound such as azomethane can be synthesized from molecular nitrogen according to the catalytic cycle in which $\left(\eta^{5}\right.$-cyclopentadienyl)tricarbonylmanganese $\left(\mathrm{CpMn}(\mathrm{CO})_{3}\right)$ is used as the catalyst. However, repetition of the catalytic cycle is prevented by side reactions which deactivate the catalyst. Some studies ${ }^{5-10}$ have been reported on the reversible nitrogenation of transition-metal complexes. Catalytic reduction of the coordinated nitrogen molecules under mild conditions is not yet possible. $^{5}$
We have investigated the chemical behavior of several polymer metal complexes. ${ }^{11-18}$ In the course of investigation on certain synthetic polymermetal complexes, electrostatic, hydrophobic, and neigbouring-group effect have been observed. It has been suggested by other workers ${ }^{19,20}$ that active complex species fixed on the polymer chains are stabilized as a result of suppression of the side reactions in which active sites are decomposed.

This paper describes the preparation of some polymer bound dinitrogen complexes from $\left(\eta^{5}\right.$ vinylmethylcyclopentadienyl)tricarbonylmanganese (VCM)-styrene (ST) and VCM-PY (PY= $\mathrm{N}$-vinylpyrrolidone) copolymers and the characteristics of the dinitrogen complexes.

\section{EXPERIMENTAL}

\section{Materials}

Freshly-distilled styrene and $N$-vinylpyrrolidone were used for the copolymerizations. ( $\eta^{5}$-methylcyclopentadienyl)tricarbonylmanganese (MCM) 
was purchased from Alfa Chemicals Co. and used after distillation under reduced pressure. Acetyl derivative of MCM was prepared in a manner similar to that for $\left(\eta^{5}\right.$-acetylcyclopentadienyl)tricarbonylmanganese reported by Kozikowski, ${ }^{21}$ and Pittman, Jr. et al. ${ }^{22}$ The light-yellow oily liquid of the acetyl derivative was obtained in a yield of $c a$ : $80 \%$. $\alpha$-hydroxyethyl derivative of MCM was prepared by the reduction of the acetyl derivative with lithium aluminium hydride $^{22}$ (yield, $c a .75 \%$ ). VCM was obtained by the dehydration of the $\alpha$-hydroxyethyl derivative. ${ }^{23}$ A mixture of the $\alpha$-hydroxyethyl derivative $(40 \mathrm{~g}$, $150 \mathrm{mmol}), \mathrm{KHSO}_{4}(2.4 \mathrm{~g}, 18 \mathrm{mmol})$, and $t$ butylcatechol $(0.4 \mathrm{~g}, 4 \mathrm{mmol})$ was heated at 130 $150^{\circ} \mathrm{C}$ and $9 \times 10^{-2}$ atm for $20 \mathrm{~min}$. Distillation of the reaction mixture at $80-84^{\circ} \mathrm{C}$ and $2 \times 10^{-3}$ atm gave a light-yellow oily liquid of VCM (yield, $c a$. $90 \%$ ). Anal. Calcd for $\mathrm{C}_{11} \mathrm{H}_{10} \mathrm{Mn}: \mathrm{C}, 53.90 \% ; \mathrm{H}$, $4.11 \%$. Found: C, $54.28 \%$; $\mathrm{H}, 3.73 \%$.

\section{Copolymerizations}

All copolymerization reactions were carried out in benzene using azobisisobutyronitrile (AIBN) as the radical initiator at $60^{\circ} \mathrm{C}$ under nitrogen atmosphere. The amount of initiator added was $2 \mathrm{~mol} \%$ of the total monomer. VCM-ST $(1 \mathrm{~A})$ and VCMPY (1B), where A and B represent the copolymers of the styrene and $N$-vinylpyrrolidone, respectively, were purified by being precipitated twice from petroleum ether and dried in vacuo.

\section{Monomeric Dinitrogen Complex}

$\mathrm{MeCpMn}(\mathrm{CO})_{2} \mathrm{~N}_{2}$ was prepared from $\mathrm{MeCpMn}(\mathrm{CO})_{3}$ in a manner similar to that for the preparation of $\mathrm{CpMn}(\mathrm{CO})_{2} \mathrm{~N}_{2} \cdot{ }^{3}$ A THF solution of $\mathrm{MeCpMn}(\mathrm{CO})_{3}(0.5 \mathrm{~g}, 2 \mathrm{mmol})$ in THF $(100 \mathrm{ml})$ was illuminated with ultraviolet (UV) lamp at $0^{\circ} \mathrm{C}$ for $2 \mathrm{~h}$. The solution turned from light yellow to deep wine red. To this solution was added a solution of anhydrous hydrazine $(0.48 \mathrm{ml}, 15 \mathrm{mmol}$ in $2 \mathrm{ml}$ THF) at $2^{\circ} \mathrm{C}$. After standing for $2 \mathrm{~h}, 0.05 \mathrm{M} \mathrm{CuSO}_{4}$ $(0.05 \mathrm{ml})$ and $30 \% \mathrm{H}_{2} \mathrm{O}_{2}$ solution $(3.4 \mathrm{ml}, 30 \mathrm{mmol})$ were added and the reaction mixture was kept at $-40^{\circ} \mathrm{C}$ for $1 \mathrm{~h}$. The solution was evaporated to dryness at $0^{\circ} \mathrm{C}$ under reduced pressure. $\mathrm{MeCpMn}(\mathrm{CO})_{2} \mathrm{~N}_{2}$ was sublimed from the residue at $20^{\circ} \mathrm{C}$ and $10^{-3} \mathrm{~atm}$. A light-yellow oily product of $\mathrm{MeCpMn}(\mathrm{CO})_{2} \mathrm{~N}_{2}$ was obtained in a yield of about $20 \%$. Anal. Calcd for $\mathrm{C}_{8} \mathrm{H}_{7} \mathrm{~N}_{2} \mathrm{O}_{2} \mathrm{Mn} ; \mathrm{C}, 44.05 \% ; \mathrm{H}$,
$3.24 \% ; \mathrm{N}, 12.84 \%$. Found: $\mathrm{C}, 44.52 \% ; \mathrm{H}, 3.65 \%$; N, $12.51 \%$. Key bands of the infrared (IR) spectra (neat) in $\mathrm{cm}^{-1}$ were 3101 (Cp ring $\mathrm{CH}$ str), $2160\left(\mathrm{~N}_{2}\right.$ str), 2002, 1910 (CO str), 672, 638 (Mn-CO bands).

\section{Polymer-Bound Dinitrogen Complexes}

The polymer-bound dinitrogen complexes, 4A and $4 \mathrm{~B}$, were prepared from the mono-substituted tetrahydrofuran (THF) derivatives of $1 \mathrm{~A}$ and $1 \mathrm{~B}$, respectively. Molarities of the polymer complexes are represented by unit moles of the manganese in the copolymer. The THF derivative of $1 \mathrm{~A}(2 \mathrm{~A})$ and that of $1 \mathrm{~B}(2 \mathrm{~B})$ were obtained by substitution of one of the carbonyl groups by a THF molecule with illumination. An argon-saturated solution of $1 \mathrm{~A}$ or $1 \mathrm{~B}(3.5 \mathrm{mmol})$ in $50 \mathrm{ml}$ of THF was illuminated for $2 \mathrm{~h}$ at $2^{\circ} \mathrm{C}$. With the illumination of light, the initially-light-yellow solution turned to deep wine red. Molar fractions of the manganese complex unit and styrene or $N$-vinylpyrrolidone unit, represented by $m$ and $n$, respectively, were determined by both elemental analysis and spectrophotometry: the value of $m$ was determined spectrophotometrically, using the visible absorption spectra of argonsaturated THF solutions of the copolymers prepared under dim light in order to prevent a substitution reaction of the carbonyl group by the THF molecule. The visible absorption spectrum of $1 \mathrm{~A}$ in the argon-saturated THF solution is shown in Figure 1 (curve a). The absorption peak of the band at $328 \mathrm{~nm}$ and its molar extinction coefficient of $1 \mathrm{~A}$ are the same as those of $1 \mathrm{~B}$ regardless of the value of $m$. Consequently, the value of $m$ may be determined spectrophotometrically using $\varepsilon=1330 \mathrm{~mol}^{-1} \mathrm{dm}^{3}$ at $328 \mathrm{~nm}$. The methods for preparing the polymerbound dinitrogen complexes were 1), oxidation of the coordinated hydrazine and 2) reaction of the THF derivatives, $2 \mathrm{~A}$ and $2 \mathrm{~B}$, with nitrogen gas. These methods are simply represented by "indirect method" and "direct method," respectively. The indirect method was carried out as follows. To a THF solution of $1 \mathrm{~A}$ or $1 \mathrm{~B}(12 \mathrm{mmol}$ in $50 \mathrm{ml})$ was added a small excess of anhydrous hydrazine $(0.42 \mathrm{ml}, 13 \mathrm{mmol})$ at $0^{\circ} \mathrm{C}$. After $1 \mathrm{~h}, 30 \% \mathrm{H}_{2} \mathrm{O}_{2}$ solution $(3.0 \mathrm{ml}, 26 \mathrm{mmol})$ and $0.05 \mathrm{M} \mathrm{CuSO}_{4}$ $(0.05 \mathrm{ml})$ were added successively and stirred at $-40^{\circ} \mathrm{C}$ for $1 \mathrm{~h}$. A crude-polymer-bound dinitrogen complex was precipitated by pouring the THF solution into petroleum ether. The product was purified by precipitation twice from petroleum 
ether. The polymer-bound dinitrogen complexes were obtained as a pale-yellow powder. The direct preparation was carried out as follows. The polymer $1 \mathrm{~A}$ or $1 \mathrm{~B}(3.5 \mathrm{mmol})$ was dissolved into $30 \mathrm{ml}$ of $\mathrm{Ar}$ saturated THF-benzene $(1: 5 \mathrm{v} / \mathrm{v})$. The solution was illuminated with a UV lamp for $2 \mathrm{~h}$ at $2^{\circ} \mathrm{C}$. The solution was kept under $3 \mathrm{~atm}$ of $\mathrm{N}_{2}$ at $0^{\circ} \mathrm{C}$ for $10 \mathrm{~h}$. The polymer-bound dinitrogen complex was precipitated from a large amount of petroleum ether and dried under nitrogen.

\section{Instruments}

A $100 \mathrm{~W}$ high-pressure mercury lamp was used as the light source for UV illumination. The distance between the reaction vessel $(100 \mathrm{ml}$ round bottomed pyrex flask) and the lamp was kept at $35 \mathrm{~cm}$. The infrared spectra were measured in $\mathrm{KBr}$ disks or neat liquid films on a Hitachi Model 200-10 spectrometer. Absorption spectra were measured on a Hitachi Model 320 spectrophotometer. Viscosities were measured in THF solutions, using a Ub́belohdetype viscometer at $25 \pm 0.1^{\circ} \mathrm{C}$.

\section{RESULTS AND DISCUSSION}

The acetyl derivative of MCM was prepared by the aluminium chloride-catalyzed acetylation of MCM with acetyl chloride in carbon disulfide. Reduction of the acetyl derivative with lithium aluminium hydride in diethyl ether yielded the $\alpha$ hydroxyethyl derivative, and dehydration of it with potassium bisulfate gave VCM as a light-yellow oily product. Two isomers of the vinyl derivatives $(1,2-$
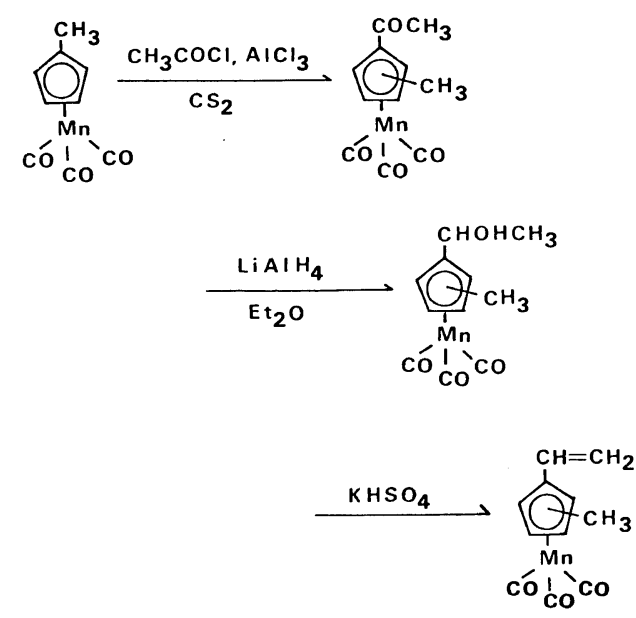

Scheme 1. and 1,3-substituents) of VCM presumably exist in the product and were used without being separated.

AIBN-initiated copolymerization reaction of VCM with ST or PY gave the copolymer 1A or 1B,<smiles>C=Cc1ccc([N+]([O-])([O-])[O-])cc1</smiles>

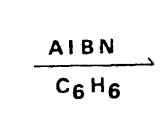

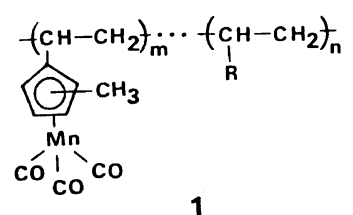

$$
\begin{aligned}
& \text { A: } R=0 \\
& \text { B: } \quad R=\square^{\prime}=0
\end{aligned}
$$

Scheme 2.

respectively, as a pale yellow powder. The copolymers $1 \mathrm{~A}$ and $1 \mathrm{~B}$ are soluble in THF and other ordinary organic solvents. The values of $m$ and $n$ obtained by elemental analysis agree with those obtained by means of spectrophotometry within experimental error. The analytical data of the copolymers prepared are shown in Table I.

Solutions of the mono THF-coordinated derivatives of $1 \mathrm{~A}$ and $1 \mathrm{~B}$, represented by $2 \mathrm{~A}$ and $2 \mathrm{~B}$, respectively, were obtained by illumination of the THF solutions of $1 \mathrm{~A}$ and $1 \mathrm{~B}$, respectively, under an argon atmosphere. Spectral change of $1 \mathrm{~A}$ in the THF solution during UV illumination is shown in Figure 1. With illumination of the UV lamp, the color of the solution turned from light yellow to deep wine red. Similar color changes were observed in THF solutions of $1 \mathrm{~B}$ and $\mathrm{MeCpMn}(\mathrm{CO})_{3}$ and are attributed to the substitution of the carbonyl group by the THF molecule. ${ }^{1,2}$ In the spectral change

1

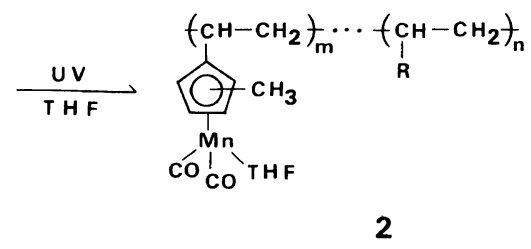


Table I. Copolymerization of $\left(\eta^{5}\right.$-vinylmethylcyclopentadienyl)tricarbonylmanganese $\left(\mathbf{M}_{1}\right)$ with styrene or $N$-vinylpyrrolidone ${ }^{a}$

\begin{tabular}{|c|c|c|c|c|c|c|}
\hline \multirow{2}{*}{ Copolymer } & \multicolumn{3}{|c|}{ Found (Calcd) $/ \%$} & \multirow{2}{*}{$\begin{array}{l}\text { Mole fraction } \\
\text { of } M_{1} \text { in feed }\end{array}$} & \multirow{2}{*}{$\begin{array}{l}\text { Mole fraction of } \\
M_{1} \text { in copolymer }\end{array}$} & \multirow{2}{*}{$\frac{[\eta]^{\mathrm{b}}}{\mathrm{dl} \mathrm{g}^{-1}}$} \\
\hline & $\mathrm{C}$ & $\mathrm{H}$ & $\mathrm{N}$ & & & \\
\hline $1 \mathrm{~A}-1$ & $\begin{array}{c}69.18 \\
(70.04)\end{array}$ & $\begin{array}{c}5.14 \\
(5.40)\end{array}$ & & 0.50 & 0.37 & 0.0788 \\
\hline $1 \mathrm{~A}-2$ & $\begin{array}{c}79.74 \\
(80.99)\end{array}$ & $\begin{array}{c}6.69 \\
(6.55)\end{array}$ & & 0.33 & 0.15 & 0.114 \\
\hline $1 \mathrm{~B}-1$ & $\begin{array}{c}56.94 \\
(56.87)\end{array}$ & $\begin{array}{c}5.69 \\
(4.85)\end{array}$ & $\begin{array}{c}3.14 \\
(3.23)\end{array}$ & 0.33 & 0.57 & 0.0628 \\
\hline $1 \mathrm{~B}-2$ & $\begin{array}{c}57.99 \\
(58.76)\end{array}$ & $\begin{array}{c}6.38 \\
(5.64)\end{array}$ & $\begin{array}{c}6.47 \\
(5.45)\end{array}$ & 0.17 & 0.37 & 0.102 \\
\hline
\end{tabular}

a $1 \mathrm{~A}$ and $1 \mathrm{~B}$ represent the VCM-ST and VCM-PY copolymers, respectively.

b Intrinsic viscosities in THF solutions at $25 \pm 0.1^{\circ} \mathrm{C}$.

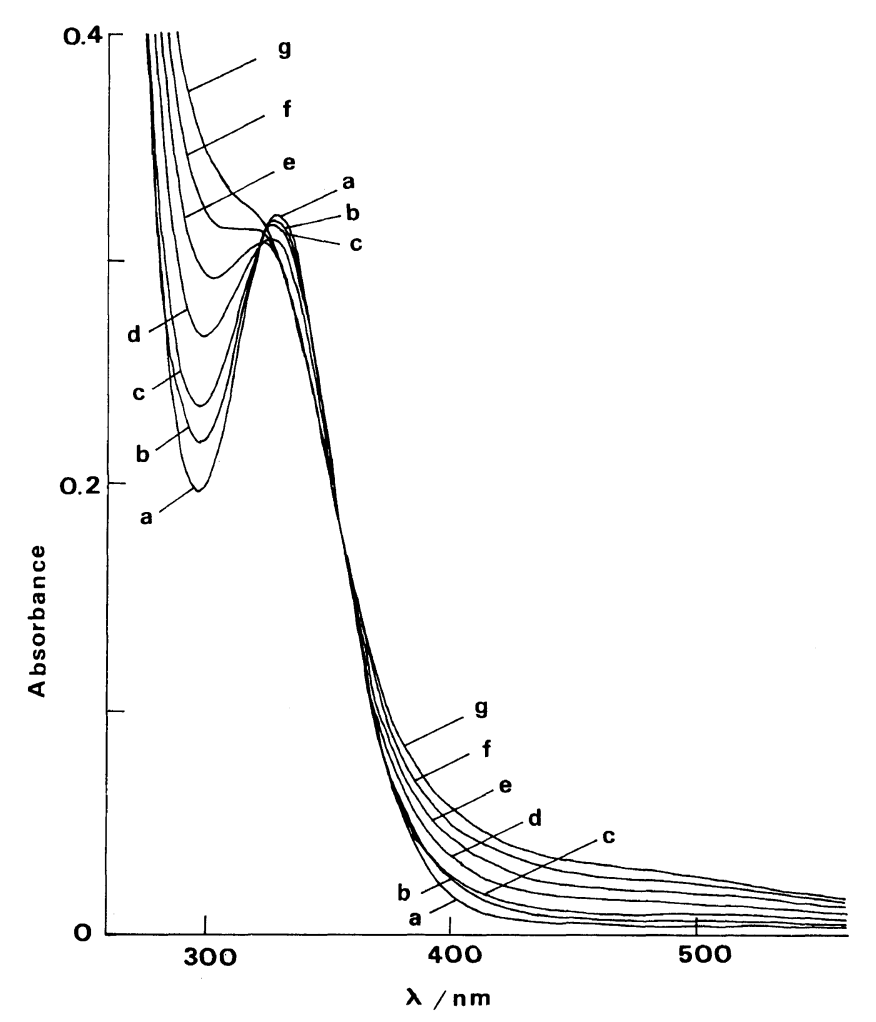

Figure 1. Spectral change in the THF solution of $2.50 \times 10^{-4}$ moll ${ }^{-1} 1 \mathrm{~A}$ with UV illumination at $2^{\circ} \mathrm{C}$ under argon. Illumination time / min: a, 0; b, 20; c, 40; d, 120; e, 160; f, 220; g, 280. 
caused by illumination of $1 \mathrm{~A}$ and $1 \mathrm{~B}$ solutions, isosbestic points could be observed at $324 \mathrm{~nm}$ and $352 \mathrm{~nm}$ within an irradiation time of $2 \mathrm{~h}$. The spectral changes within $2 \mathrm{~h}$ are caused by the exchange of one of the carbonyl groups by a THF molecule. These isosbestic points, however, could not be observed when the irradiation time was prolonged. This is presumably due to the replacement of the second carbonyl group. It may be concluded that about one Mn-bound carbonyl group on each polymer complex is substituted by the solvent molecule during 2 hours of irradiation under the conditions employed. The polymeric THF complexes, $2 \mathrm{~A}$ and $2 \mathrm{~B}$ are fairly stable compared to the monomeric THF complex, $\operatorname{MeCpMn}(\mathrm{CO})_{2-}$ THF. No appreciable spectral change in $2 \mathrm{~A}$ and $2 \mathrm{~B}$ in THF solution was observed during 100 minutes of standing at $2^{\circ} \mathrm{C}$ under Ar. On the other hand, when $\mathrm{MeCpMn}(\mathrm{CO})_{2}-\mathrm{THF}$ was allowed to stand under the same conditions a rapid spectral change was observed within several minutes.

The polymer-bound dinitrogen complexes (4A and 4B) were prepared by 1) oxidation of the coordinated hydrazine (indirect method) and 2) a direct reaction between nitrogen molecule and the THF complexes, $2 \mathrm{~A}$ or $2 \mathrm{~B}$ (direct method).

The polymeric hydrazine complexes, $3 \mathrm{~A}$ and $3 \mathrm{~B}$, were obtained by the reaction of $2 \mathrm{~A}$ and $2 \mathrm{~B}$, respectively, with hydrazine in $\mathrm{THF}$ at $2^{\circ} \mathrm{C}$. As a result of the formation of the hydrazine derivative, the color of the solution turned from wine red to orange. The oxidation reaction of the coordinated hydrazine to dinitrogen was carried out using the two-electron oxidizing agent, $\mathrm{H}_{2} \mathrm{O}_{2}-\mathrm{Cu}^{2+}$, at $-40^{\circ} \mathrm{C}$.

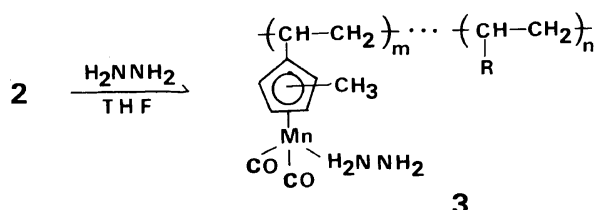

\section{3}

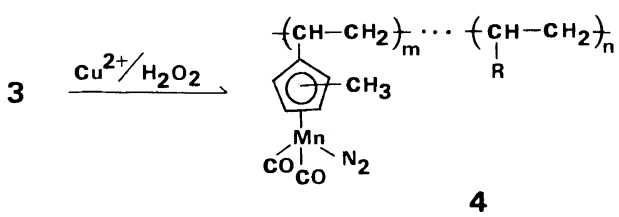

Scheme 4.
Preparation of the $\mathrm{N}_{2}$-coordinated polymer complexes by the direct method was carried out in THFbenzene $(1: 5 \mathrm{v} / \mathrm{v})$. The substitution reaction of the THF by nitrogen molecule proceeded under relatively mild conditions. Solid-polymer-bound di-

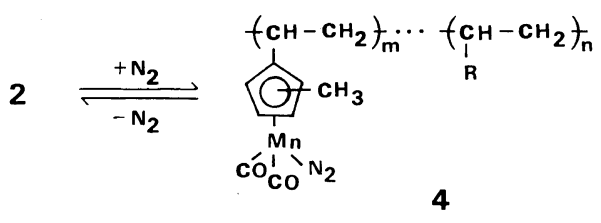

Scheme 5.

nitrogen complexes were obtained by precipitation from petroleum ether and dried under nitrogen stream. The IR spectra of the polymer-bound dinitrogen complexes showed a characteristic $v_{\mathrm{N}_{2}}$ band at $2160 \mathrm{~cm}^{-1}$.

A possible structure for the polymer-bound dinitrogen complexes in THF solution is given in Figure 2.

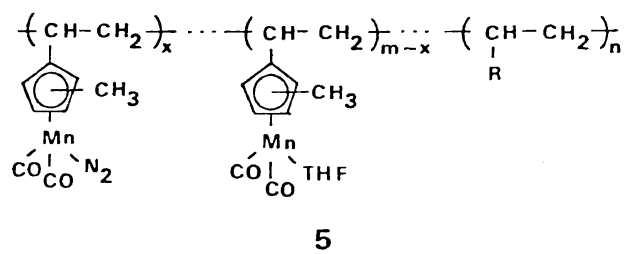

Figure 2. Possible structure of the polymer-bound dinitrogen complex in the THF solution.

When the polymer-bound dinitrogen complexes are obtained as a solid, a part of the THF and/or nitrogen molecules coordinated to the manganese atoms are presumably released during the process of the precipitation and drying under nitrogen. The precipitates of the polymer-bound dinitrogen complexes were dried in vacuo for several hours. The resulting powder became less soluble in THF and other ordinary organic solvents.

It was reported ${ }^{3}$ that the characteristic $v_{\mathrm{N}_{2}}$ band was observed for the product obtained by the reaction of $\mathrm{CpMn}(\mathrm{CO})_{2}-\mathrm{THF}$ with nitrogen molecule in the following manner. Nitrogen gas was pressurized at 150 atm into a solution of $\mathrm{CpMn}(\mathrm{CO})_{2}-\mathrm{THF}$ for $24 \mathrm{~h}$ and the THF was then removed at room temperature in vacuo. The solid products were obtained by sublimation of the residue. $\mathrm{CpMn}(\mathrm{CO})_{2} \mathrm{~N}_{2}$ in the products was iden- 
Table II. IR frequencies $\left(\mathrm{cm}^{-1}\right)^{\mathrm{a}}$

\begin{tabular}{|c|c|c|c|c|c|c|c|c|c|c|}
\hline \multirow{2}{*}{$\frac{\text { Compound }}{1 \mathrm{~A}-1^{\mathrm{b}}}$} & \multicolumn{2}{|c|}{$v_{\mathrm{C}-\mathrm{H}}(\mathrm{Cp})$} & \multirow[t]{2}{*}{$v_{\mathrm{N}_{2}}$} & \multicolumn{2}{|c|}{$v_{\mathrm{CO}}$} & \multicolumn{2}{|c|}{$v_{\mathrm{C}-\mathrm{c}}(\mathrm{Ph})$} & \multirow[t]{2}{*}{$v_{\mathrm{C}-\mathrm{C}}(\mathrm{PY})$} & \multicolumn{2}{|c|}{$v_{\mathrm{Mn}-\mathrm{Co}}$} \\
\hline & 3070 sh & $3045 \mathrm{sh}$ & & 2002vs & $1920 \mathrm{vs}$ & $1601 \mathrm{~s}$ & $1490 \mathrm{~s}$ & & $662 \mathrm{~s}$ & $638 s$ \\
\hline $4 \mathrm{~A}-1^{\mathrm{c}}$ & $3070 \mathrm{sh}$ & 3050 & $2160 \mathrm{~s}$ & 2002vs & $1920 \mathrm{vs}$ & $1598 \mathrm{~s}$ & $1492 \mathrm{~s}$ & & $660 \mathrm{~s}$ & $637 \mathrm{~s}$ \\
\hline $1 \mathrm{~B}-1^{\mathrm{b}}$ & 3070 & 3050sh & & $2002 \mathrm{cs}$ & 1920vs & & & 1285 & $660 \mathrm{~s}$ & $637 \mathrm{~s}$ \\
\hline $4 \mathrm{~B}-1^{\mathrm{c}}$ & $3070 \mathrm{sh}$ & $3050 \mathrm{sh}$ & $2160 \mathrm{~s}$ & $2003 v s$ & $1918 v s$ & & & 1282 & $662 \mathrm{~s}$ & $640 \mathrm{~s}$ \\
\hline $\operatorname{MeCpMn}(\mathrm{CO})_{3}$ & \multicolumn{2}{|c|}{3102} & & $2005 v s$ & $1910 \mathrm{vs}$ & & & & $670 \mathrm{~s}$ & $640 s$ \\
\hline $\mathrm{MeCpMn}(\mathrm{CO})_{2} \mathrm{~N}_{2}$ & \multicolumn{2}{|c|}{3101} & $2160 \mathrm{~s}$ & 2002vs & 1910vs & & & & $672 \mathrm{~s}$ & $638 \mathrm{~s}$ \\
\hline
\end{tabular}

${ }^{a} \mathrm{KBr}$ disks, except those for $\mathrm{MeCpMn}(\mathrm{CO})_{3}$ and $\mathrm{MeCpMn}(\mathrm{CO})_{2} \mathrm{~N}_{2}$. vs, very strong; s, strong; sh, shoulder.

b Except for the $v_{\mathrm{C}-\mathrm{C}}(\mathrm{ph})$ band, IR frequencies of the key bands of $1 \mathrm{~A}-1,1 \mathrm{~B}-1,4 \mathrm{~A}-1$, and $4 \mathrm{~B}-1$ are the same as the corresponding bands of $1 \mathrm{~A}-2,1 \mathrm{~B}-2,4 \mathrm{~A}-2$, and 4B-2, respectively.

c Prepared by the direct method in THF-benzene $(1: 5 \mathrm{v} / \mathrm{v})$ at $3 \mathrm{~atm}$ of $\mathrm{N}_{2}$ and $2^{\circ} \mathrm{C} .4 \mathrm{~A}-1$ and $4 \mathrm{~B}-1$ were synthesized from $1 \mathrm{~A}-1$ and $1 \mathrm{~B}-1$, respectively.

tified by means of its characteristic IR band. However, our attempt to prepare pure $\mathrm{MeCpMn-}$ $(\mathrm{CO})_{2} \mathrm{~N}_{2}$ by the direct reaction of MeCpMn(CO) $)_{2}$-THF with $\mathrm{N}_{2}$ was unsuccessful.

For the polymer-bound dinitrogen complexes, an end-on type coordination of the dinitrogen to the manganese is suggested from the intense $v_{\mathrm{N}_{2}}$ band arround $2160 \mathrm{~cm}^{-1} .^{1,2}$ The infrared frequencies of the main peaks of the polymer-bound dinitrogen complexes, copolymers $1 \mathrm{~A}$ and $1 \mathrm{~B}, \mathrm{MeCpMn}$ $(\mathrm{CO})_{2} \mathrm{~N}_{2}$, and $\mathrm{MeCpMn}(\mathrm{CO})_{3}$ are listed in Table II. The IR peaks of the $v_{\mathrm{N}_{2}}$ bands of the polymerdinitrogen complexes are the same as that of $\operatorname{MeCpMn}(\mathrm{CO})_{2} \mathrm{~N}_{2}$.

A THF solution of the polymer-bound dinitrogen complexes, $4 \mathrm{~A}$ and $4 \mathrm{~B}$, was made to stand for $3 \mathrm{~h}$ at room temperature under argon. The solution was poured into petroleum ether and the powder was collected. The IR spectra of the powder had no $v_{\mathrm{N}_{2}}$ band and no appreciable change in the IR band was observed except for the $v_{\mathrm{N}_{2}}$ band. This seems to indicate that the nitrogen molecules coordinated to the polymer complexes could be eliminated without appreciable decomposition of the polymer complexes.

A conventional method was employed for making a comparison of the stabilities of the dinitrogen complexes. The changes in the $v_{\mathrm{N}_{2}}$ band strength of the dinitrogen complexes were followed as a function of the time. The polymer-bound dinitrogen complexes, $4 \mathrm{~A}$ and $4 \mathrm{~B}$, were stable in air at room temperature for several days whereas the monomeric dinitrogen complex was air sensitive and the $v_{\mathrm{N}_{2}}$ band of $\mathrm{MeCpMn}(\mathrm{CO})_{2} \mathrm{~N}_{2}$ disappeared after $17 \mathrm{~h}$ at room temperature. The $v_{\mathrm{N}_{2}}$ band strength of

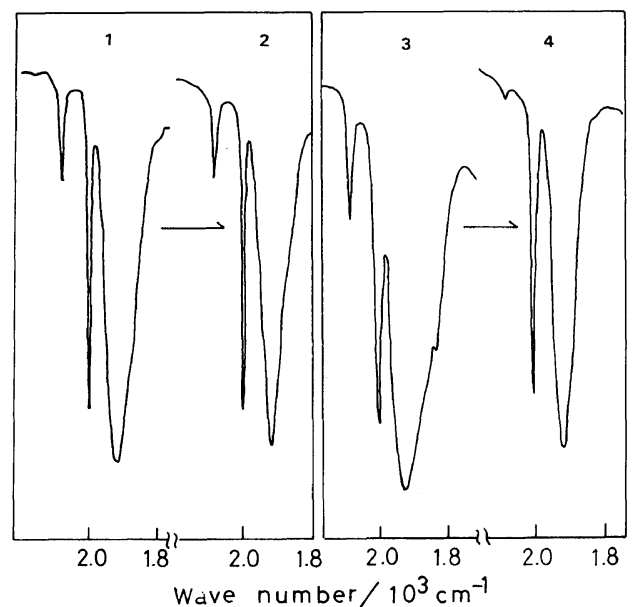

Figure 3. IR spectra changes of $4 \mathrm{~A}$ and $4 \mathrm{~B}$ at $90^{\circ} \mathrm{C}$ under air: 1, freshly-prepared sample of $4 \mathrm{~A} ; 2,4 \mathrm{~A}$ after $6 \mathrm{~h} ; 3$, freshly-prepared smaple of 4B; 4, 4B after $6 \mathrm{~h}$.

4A hardly changed at $90^{\circ} \mathrm{C}$ for $6 \mathrm{~h}$ but that of $4 \mathrm{~B}$ decreased appreciably under the same conditions. This indicates that the polymer-bound dinitrogen complex having styrene units is more stable thermally than that having $N$-vinylpyrrolidone units. The monomeric dinitrogen complex completely decomposed whithin several minutes under the same conditions.

We are now investigating the reactions of the coordinated nitrogen molecules using the polymerbound manganese complexes.

Acknowledgement. This work was supported in part by a Grant-in-Aid for Scientific Research from the Ministry of Eduction, Science, and Culture (No. 


\section{Polymer-Bound Dinitrogen Complexes}

447033).

\section{REFERENCES}

1. D. Sellmann, Angew. Chem. Int. Ed., 10, 919 (1971).

2. D. Sellmann and W. Weiss, Angew. Chem. Int. Ed., 16, 880 (1977).

3. D. Sellmann, Z. Naturforsch., 25b, 890 (1970).

4. D. Sellmann, Angew. Chem. Int. Ed., 11, 534 (1972).

5. D. Sellmann, Angew. Chem. Int. Ed., 17, 269 (1978).

6. D. F. Harrison, E. Weissberger, and H. Taube, Science, 159, 320 (1968).

7. W. E. Silverthorn, J. Chem. Soc., Chem. Commun., 1310 (1971).

8. A. Yamamoto, S. Kitazume, L. S. Pu, and S. Ikeda, J. Chem. Soc., Chem. Commun., 621 (1967).

9. A. Misono, Y. Uchida, and T. Saito, Bull. Chem. Soc., Jpn., 40, 700 (1967).

10. A. Sacco and M. Rossi, J. Chem. Soc., Chem. Commun., 316 (1967).

11. Y. Kurimura, K. Yamada, M. Kaneko, and E. Tsuchida, J. Polym. Sci., A-1, 9, 3521 (1971).

12. E. Tsuchida, Y. Karino, H. Nishide, and $Y$.
Kurimura, Makromol. Chem., 175, 171 (1974).

13. E. Tsuchida, Y. Karino, H. Nishide, and Y. Kurimura, Makromol. Chem., 175, 161 (1974).

14. E. Tsuchida, K. Shigehara, and Y. Kurimura, $J$. Polym. Sci., Polym. Chem. Ed., 12, 2207 (1974).

15. E. Tsuchida and H. Nishide, Adv. Polym. Sci., 24, 1 (1977).

16. H. Nishikawa, E. Terada, E. Tsuchida, and Y. Kurimura, J. Polym. Sci., Polym. Chem. Ed., 2453 (1978).

17. H. Nishide, S. Hata, K. Mihayashi, and E. Tsuchida, Biopolymers, 17, 191 (1978).

18. Y. Kurimura, K. Wakayama, H. Nishikawa, and E. Tsuchida, Makromol. Chem., 180, 339 (1979).

19. E. S. Chandrasekaram, C. Gibbons, R. H. Grubbs, and L. C. Kroll, J. Am. Chem. Soc., 97, 2128 (1975).

20. Y. Nakamura and H. Hirai, Chem. Lett., 645 (1974).

21. J. Kozikowski, J. Am. Chem. Soc., 81, 2995 (1959).

22. C. U. Pittman, Jr., G. V. Marlin, and T. D. Rounsefell, Macromolecules, 6, 1 (1973).

23. A. N. Nesmeyanov, K. N. Anismov, N. E. Kolobova, and B. Zlotina, Dokl. Akad. Nauk SSSR, 154, 72 (1964).

24. D. Sellmann, Angew. Chem. Int. Ed., 13, 639 (1974). 